\title{
Parametric Design Optimisation of Planetary Hub Reduction Equipped in Rigid Frame Dump Truck
}

\author{
Suresh $\mathrm{P}^{*}$, Raghu Vamsi Patnala \\ Research and Development Division, BEML Ltd, KGF, Karnataka, India \\ Corresponding Author - Email id*: sureshautomobile@gmail.com
}

\begin{abstract}
Article Info

Volume 8 Issue 2

Page Number : 69-80

Publication Issue :

March-April-2021

\section{Article History}

Received : 05 March 2021

Accepted : 25 March 2021

Even though the information is not leveraged in the contemporary environment, still designing the planetary hub reduction for the off-highway dump truck application without the benchmarking is a sophisticated and exceptional one, because of robust design criteria, including dynamic and maximum loads under different load spectrum. Adopting the conventional planetary gearbox/transmission design used on On/off-highway applications can cater to adequate information. However, in terms of accuracy, it substantially lags, especially for off-highway planetary hub reduction application. The primary objective of this paper is to describe the most viable and reliable procedure of designing, as well as optimizing the planetary hub reduction for off-highway dump truck in the preliminary design stage, which is suitable for industrial application with the help of gear design and simulation software called KISSsoft/KISSsys in rapid manner. Further, this paper describes designers input factors based on benchmarked and ascertained data which significantly reduces iterative steps economically. This design methodology for designing from scratch with a required reduction ratio of 7.235:1 in a short space constraint carried out for 100-ton dump truck, with the gradeability which suits the design requirements and the results of optimised design compared with existing design used for similar tonnage BEML dump truck with the same reduction ratio in higher constructive volume. The compared results found to be in very well accordance concerning the safety factor, life cycle and also the system-level weight of the planetary gear train reduced by $17 \%$ in a diminished constructive volume for the optimized new design. This design approach is versatile and time saving and can also be used as an integral approach which is suitable from the conceptual design stage to proto development for industrial application.
\end{abstract}

Published : 28 March 2021
Keywords : Hub Reduction, Final Drive, Rear Axle, Off-Road Equipment, Dumper, Planetary Gear Train. 


\section{INTRODUCTION}

On certain occasions, new product development is often the outcome of a contemporary requirement for an existing product. The present project was taken up in such a manner of achieving the same planetary reduction ratio in diminished outer diameter (OD) of the ring gear for the existing rear axle due to the requirement of upgrading the existing product with flange type wheel/rim. Mining industries are driving towards improving efficiency in production and hauling in open cast mining. The requirement of increased tonnage per hauling substantially increased the size of rigid frame dump trucks. In deep pit mining, the road covers a range of 100-300 meters in vertical lift. To reduce the road construction cost, these deep pit mines must increase the grade of the $\operatorname{road}[1]$.

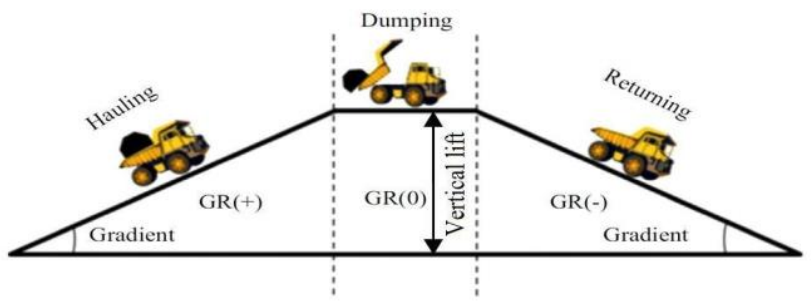

Figure 1: Schematics of Hauling, Dumping and Returning of a dump truck on different vertical lifts

Besides, the increase in hauling tonnage, hauling distance, vertical lift and resultant grades are making the demand for heavily-laden dump trucks with higher gradeability that is operated on rough roads conditions. This force mining equipment manufacturers to design a dump truck with higher gradeability. Earthmoving equipment manufacturers have to achieve higher gradeability of the heavilyladen rigid dump truck by accommodating higher horsepower engines with deep ratio transmission and final drive. Installing higher horsepower engines is not a smart choice because its limitations such as producing torque from rest, producing maximum power only at certain engine speeds and achieving regulatory emission norms with higher horsepower is a difficult one [2]. In the same fashion, achieving a higher ratio in gearbox in a shorter space is a tangled one. In this kind of constraint, the total reduction ratio can be obtained by double-reduction final drive optimally. The rear-axle in rigid dump trucks is the final stage of a constant reduction transmission in a powertrain which delivers torque to the driving wheels and has no steering ability. The first phase of reduction accrues in spiral bevel differential and the second phase of the reduction in planetary type reduction accrue on wheel-end are addressed as hub reduction. Increasing the differential ratio is proportional of increasing the size of the differential housing, which relates to the reduction in ground clearance and brings the differential banjo housing nearer to the ground. The higher risk persists on bringing the differential housing near the ground, especially in unpaved job site roads with harsh mining environments. Therefore, one of the smart option remnants to power train designers are to provide maximum reduction in the hub end. Simple planetary hub reduction design would meet the design requirements more economically than a bull gear and pinion design. Hub reduction planetary gear train (PGT) gives ample advantage of its nature to deliver the torque in the wheel directly and reduce the driveshaft stresses.

Simultaneously, production efficiency can be improved by reducing the downtime by improving the serviceability. Assembling and disassembling takes ample time for wedge type wheel mounting design over the flange type disc wheel mounting design. Most of the mining industries demand for a dump truck with flange type disc wheel mounting design over the conventional wedge type wheel mounting design.

Flange type disc wheels mounting design provides easy removal/installation of the tires which cut short the span of corrective maintenance. Further present 
notice inviting tender (NIT) requirements of Indian mining industries are demanding for flange type wheel mounting design as essential eligibility criteria for the 100 ton class dump truck.

\section{BACKGROUND AND CHALLENGES}

\section{A. WEDGE TYPE RIM/WHEEL MOUNTING}

For many years the 5-piece Wedge type rim was widely used in off-road dump trucks. The five-piece consists of rim base, bead seat band, two flanges, and lock ring [3]. The rim is firmly held in place by a stud, nut and clamp assembly. Dismantling and assembling tires and wheels take ample time in multi-piece wheel rims design. In wide-base wedge rim mounting the rim base can be placed closer to the wheel hub OD with the minimum clearance. In this case, the designer gets good leverage on maximizing the OD of the ring gear. Wedge type rim/wheel mounted on dump truck shown in figure; 2 along with 2D schematics.
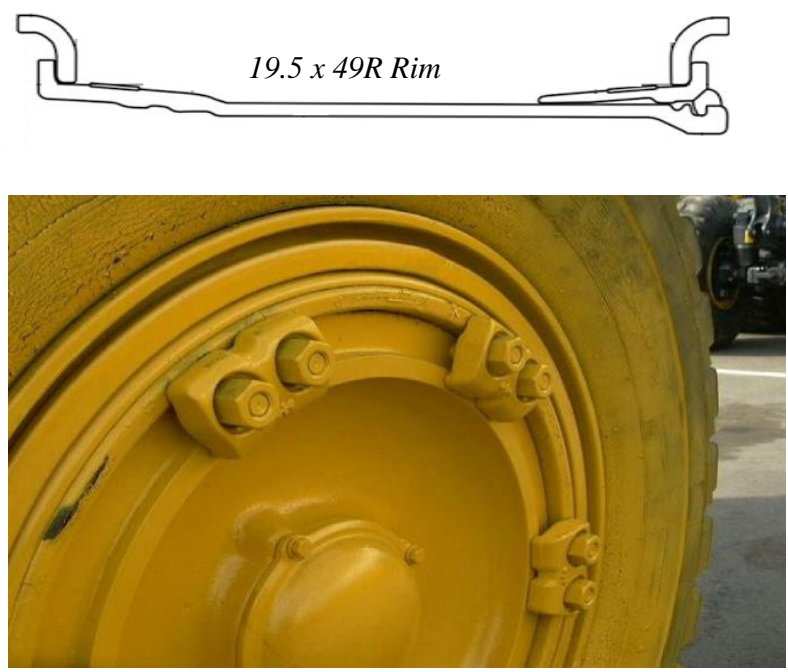

Figure 2. Wedge type wheel/rim on the dump truck

\section{B. DISC RIM/WHEEL MOUNTING}

In disc/flange type rim, the disc permanently welded into the ID of the rim base. The disc can be located at an offset based on application to ensure proper clearance and wheel track of the vehicle [3].

Upgradation of disc/flange type rim over the wedge type for the fixing of the wheels facilitates wheel assembling and dismantling which leads to improved maintainability. Disc type rim/wheel mounted on dump truck shown in figure; 3 along with 2D schematics.

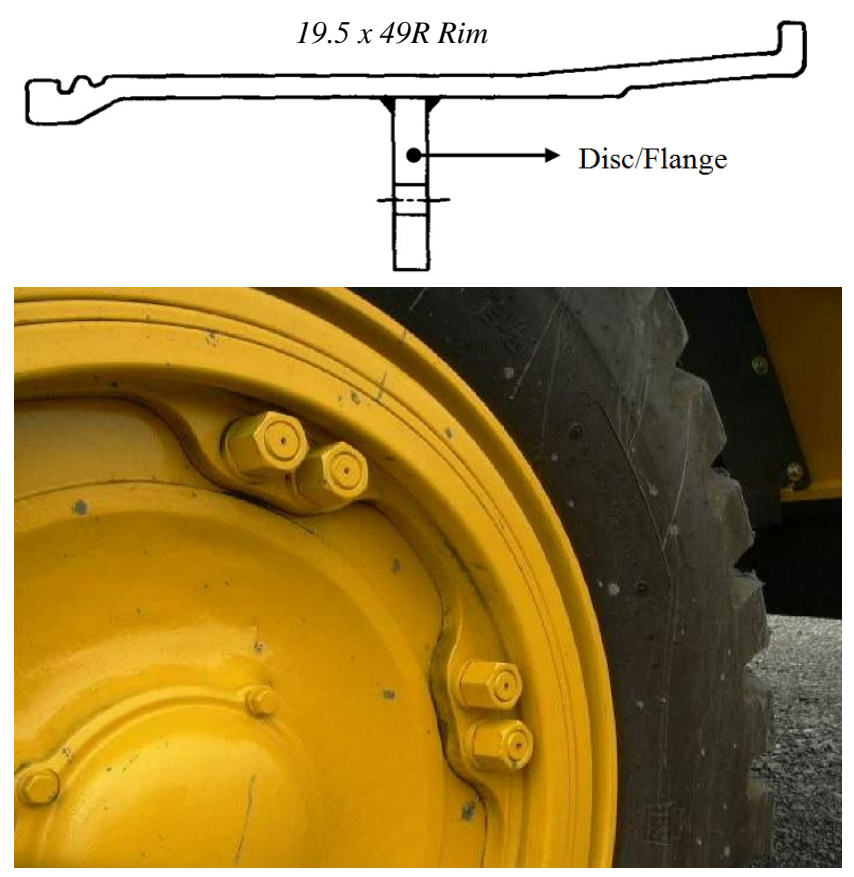

Figure 3. Disc wheel/rim mounted on the dump truck

The major challenge for the design engineer is to provide maximum reduction ratio in the planetary hub reduction in a diminished ID for flanged type wheel rim design. As the disc/flange is welded in the ID of the rim base, the maximum ID is reduced which results in diminished ring gear OD and wheel Hub OD. In the disc rim/wheel mounting design the maximum OD of the ring gear diminished by around $20 \%$ for the same size tire. 


\begin{tabular}{|c|l|}
\hline $\begin{array}{l}\text { Maximum ID of Ring } \\
\text { Gear when using wedge } \\
\text { type rim for 27xR49 Tire }\end{array}$ & $\begin{array}{l}\text { Maximum ID of Ring } \\
\text { Gear when using flange } \\
\text { type rim for 27xR49 } \\
\text { Tire }\end{array}$ \\
\hline $1026 \mathrm{~mm}$ & \multicolumn{1}{|c|}{$850 \mathrm{~mm}$} \\
\hline
\end{tabular}

Table 1. Outer dimensional constraint of ring gear while using wedge and flange type rim configuration for the same size of Tire.

In this context the PGTs should have the same ratio to meet the gradeability as per design requirement and also it has to accommodate in a diminished constrictive volume because of flange type wheel/rim configuration as described above table 1 . The diminished dimensions have an ample of beneficial consequences as such as, small mass moment of inertia with reduced material consumption and the diminished dimensions of the gears allow for both heat treatment and aid to achieving higher accuracy grade in the production, which combined with the lower pitch line velocity leads to lower internal dynamic loads and to a quieter operation of the gear train, which is particularly important nowadays[4] but packaging the PGT in the reduced space is challenging one because of variable controllable and uncontrollable design factors involved. PGTs have some shortcomings and difficulties, but it's in the case of compound gear trains therefore, for a simple single stage PGT is suitable for this current application therefore, designers can easily go ahead without much research on choosing. Figure; 4. Illustrate typical hub reduction axle layout of rigid frame dump trucks.

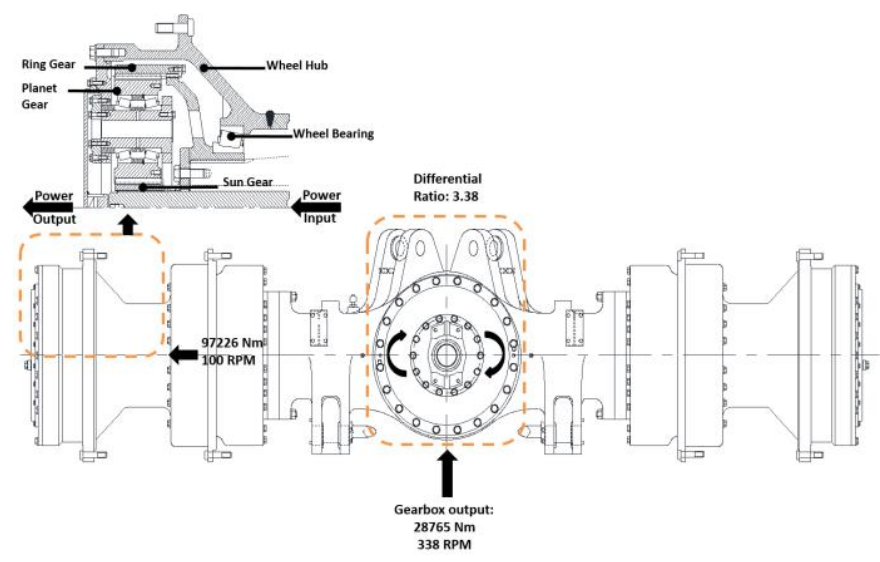

Figure 4. 2D cut sectional layout of rear axle used in dump truck

\section{METHODOLOGY}

PGTs are equipped and widespread in the different fields of engineering and in particular in the automobile sector because of beneficial consequences. Despite the advantages in PGTs, on other hand some pitfalls and shortcomings present in designing because of more complex theory than that of non-PGTs. Designing a new PGT manually by adopting international standards such as ISO 6336, DIN 3990 and AGMA 2101 is a tedious task. For every new design the standard to be referred/reviewed and it is impossible to cover all the aspects for each project. For instance, ISO 6336 part 1 to 4 contain more than 90 figures and over 20 tables for reference. Therefore, going through all the reference standards and iterating for every new design is a time-consuming one and an ample number of different variants have to be carefully evaluated and have to adopt trial and error methods also. Further different standards to be referred for different machine elements present in the gear train and the rating formulae in few international standards will not be applicable to certain species of gear tooth deterioration such as case crushing, plastic yielding, scuffing etc... The above traditional process consumes ample time and often leads to end up with inadequate design outcome. Decisions made by the design engineer during drive 
train design are critical for the performance and product quality. To overcome the above odds, design engineers need the right tool that can perform the various iterations in a short span which renounce information to make confident decisions. Therefore we chose a digital design methodology by adapting a gear train design and analysis software tool called KISSsoft. PGT design in KISSsoft/KISSsys can be categorized into three steps. The initial step is envelope packaging and the next step is macrogeometry optimisation and the final step is microgeometry optimisation.

\section{A. STRUCTURAL PACKAGING}

Structural packaging of PGTs is the process of identifying prime dimensional details to accommodate gear pairs in the available envelope with adequate wall thickness on sun, planet and ring gear. Major dimensional factors such as face width and center distance being estimated first as the ring gear OD and overall width is restricted as the result of standard tire/rim selection. To a certain extent, identifying face width and center distance in the preliminary design stage are directly integrated to the space availability and determine the overall size, weight and cost of the gear set. In addition, the load/torque capacity strongly relies on the chosen gear materials, gear quality and heat treatment. Considering all the factors in structural packaging and finding the optimal solution involves multiple and conflicting objectives becoming a tough challenge. Face width and centre distance define the overall size of the PGT with single stage reduction and centre distance alone directly linked to maximum ring gear external diameter.

The calculation methodology to be defined by selecting appropriate standards (ISO 6336, DIN 3990, AGMA 2101 etc.) and required safety factors of root and flank along with the scuffing and micro-pitting in some cases. Root and flank safety factors are set to be 1.4 and 1 as per gear rating standard [18]. The major input parameters for PGT rough sizing are power or torque, required gear ratio, normal module, speed, gear material and gear quality class. The nominal gear ratio of 7.2 is fixed with the permissible deviation percentage $1 \%$ as it is a mandate for the application requirement. Further the minimum number of sun gear teeth is fixed to 14 as the consequence of relatively low speed with coarse pitch for adequate strength with respect to the international standard guidelines for the final drive gears [5]. In accordance with ISO 6336 maximum material endurance value depends on the quality of the material, heat treatment and surface hardness [5\&6]. Consequently, if the PGT dimension can't be accommodated inside the wheel rim with minimum clearance requirements, a superior grade of material, different heat treatment or a superior gear quality class should be applied. Design input and free variable output of rough sizing is illustrated in figure; 5 .

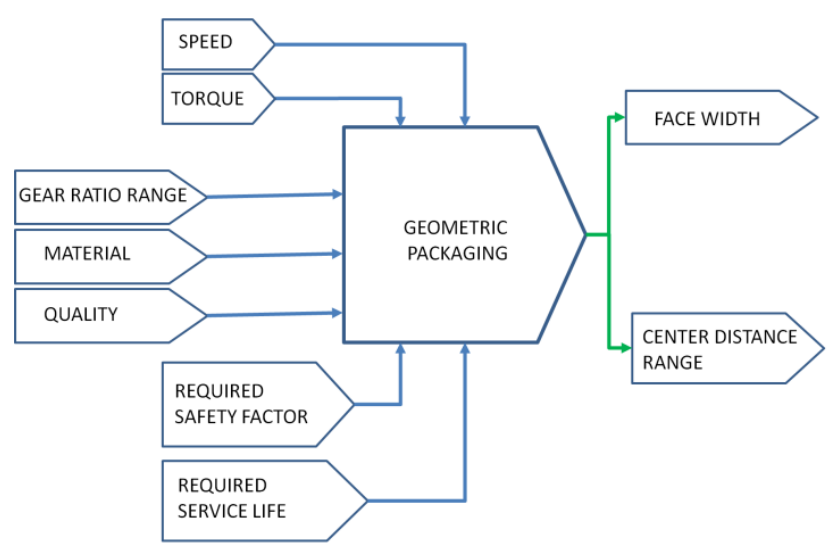

Figure 5. Design input and output of envelope packaging.

A batch of calculation can be performed in a rapid manner when the input data, required safety factor and method of calculation are fixed to extract various geometric solutions. The key task of the designer is to search for all feasible solutions which satisfy in terms of centre distance and effective face width with a reasonable quotient of face width and module. Based on the benchmarking of hub reduction PGT used in various off-highway rigid frame dump trucks and 
most of the industrial gearboxes, the ratio of face width to module is maintained below 16 to 20. Figure; 6 illustrates a batch of calculated results, filtered in terms of center distance, root diameter of ring gear and safety factors. In this premature stage itself, it is possible to estimate the power density range, size and weight of the PGT variants. Selection of smaller center distance may result in compact PGT dimension but less attractive in terms of power density. Selection of higher centre distance results in highest power density and less weight but maximum size of the ring gear is not applicable. After arriving the list of solutions, identifying the proper centre of distance in the range of $230 \mathrm{~mm}$ to $235 \mathrm{~mm}$ will give the good trade-off between dimensionally diminished PGT with low weight and suitable higher power density within available space. 9 solutions out of 125 solutions with minimum and maximum center distance were identified and all solutions are feasible for the application. In this situation the design engineer must make a choice on which solution is optimal and suitable for the given application. A straightforward approach for further selection is to find reduced weight of the gear to minimise the cost because of direct link to material cost/ $\mathrm{kg}$. In the structural packaging, accommodating is the primary target. Therefore, sufficient safety factors can be selected and further it can be improved in the next stage of the design process.

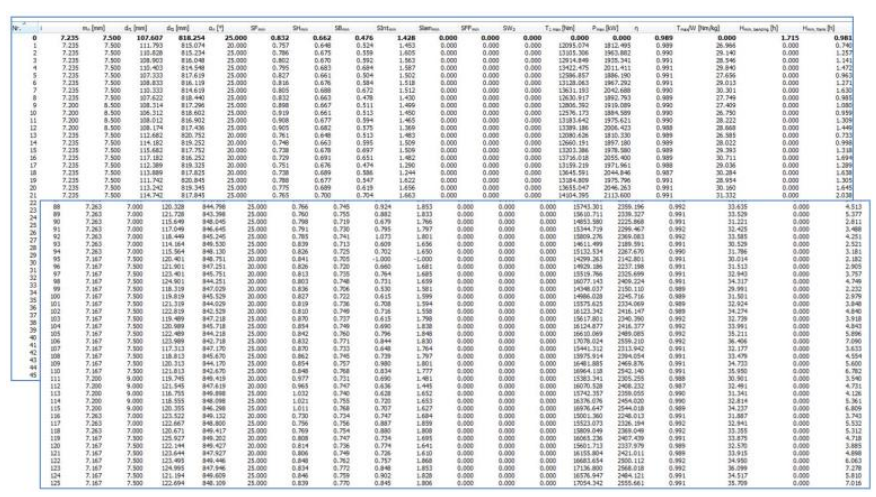

Figure 6. Batch of calculated result, filtered in terms of center distance, root diameter of ring gear and safety factors.
One solution out of nine solutions is selected based on lesser weight. Additionally, this selection approach would be to maximise the transmittable torque per $\mathrm{kg}$ Therefore, envelope packaging of gear pairs is a most critical step in PGT design where most of the prime factors like size and cost can be optimised in the premature design stage itself. The whole process of packaging is called rough sizing in KISSsoft. A result of rough sizing provides a range of possible PGT dimensions with optimal weight, dimensional size and manufacturing costs of the gear train. Packaging will not cater comprehensive and optimal results, but it's a good initiative for macro-geometry optimisation [8].

\section{B. MACRO-GEOMETRY OPTIMISATION}

Gear macro-geometry optimisation is performed once after finalizing the range of center distance and face width. Figure; 7 illustrates the process flow of macrogeometry optimisation. The key task of the macrogeometry optimisation is to carry out variational calculus of primary gear geometrical parameters, such as module, pressure angle, profile shift coefficient, number of teeth and pitch circle diameter. With KISSsoft, such a calculation can easily produce a vast range of geometric solutions. The prime challenge is to black out all unfeasible solutions and apply a clever strategy to identify an optimum one.

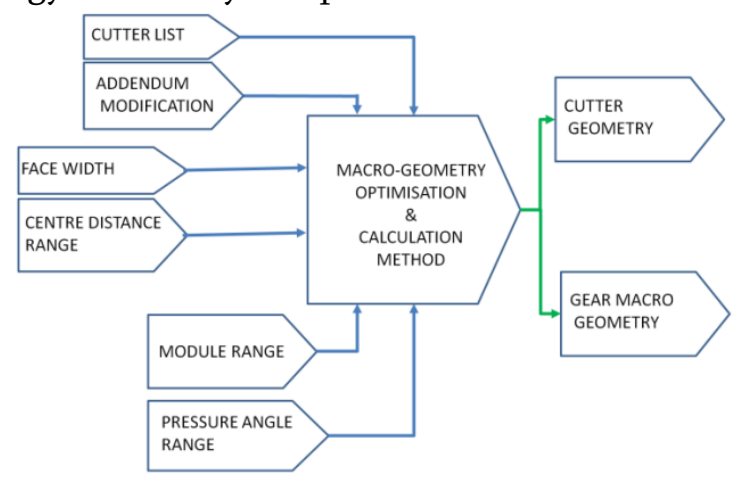

Figure 7. Design input and output of macro-geometry optimisation

Face width and centre distance achieved from the envelope packaging will be the part of input for the 
macro-geometry optimisation. The variable normal module of spur gear is defined at the interval of 7 to 10. In this study, smaller module values are not taken into account as they do not fulfil the main objective function such as low speed high torque application. Buy a single click one can iterate over a range of normal module from 7 to 10 and pressure angle in the range of $20^{\circ}$ to $25^{\circ}$, over different combination of profile shift coefficients and number of teeth by eliminating the solution with less safety factor than desired limit, with very less top land thickness (Crest width), with huge deviation from required gear ratio, with an undercut and with higher specific sliding. A $25^{\circ}$ pressure angle is quite common in earthmoving equipment, especially in final drive application where strength is preferential consideration over the noise [19]. Separating force generated by the contact of two gears will be higher for $25^{\circ}$ pressure angle gears over $20^{\circ}$. Therefore, careful evaluation to be done to achieve required life of planet bearings [20]. When packaging volume is considerably less a simple computerized algorithm will filter and extract best optimal solutions in the context of strength, gear ratio, weight, contact stiffness, etc. and best suitable overall solutions are listed, based on a weighted combination of the above listed criteria is provided. A higher addendum modification on the gear tooth results in higher root thickness and reduces the tip thickness for single tooth depth therefore; selection should be optimal to prevent pointed tooth and cutting interference. Further higher Sum of addendum modification coefficient value in conjunction with lesser number of teeth of the paired gears may cause excess bottom clearance, lubricant pressure, interference, etc. [9]. Therefore, to reduce the iterative steps and to make evaluation in the easier way, a higher profile shift coefficient of 0.9 is fixed to the sun gear based on benchmarking of existing design and ascertained values for low-speed gears. Therefore, after applying the addendum modification values multiple tasks are ensured such as no undercut, no pointed tooth and equalised bending and fatigue life. Further the major failures encountered in gears are tooth fracture and surface failure [10]. Therefore, designers should be extremely cautious about selection of macro-geometry adjustments to counterattack the tooth fracture and surface failure. By limiting distribution of addendum modification in an accurate manner can prevent the demerits of addendum modification. Figure; 8 illustrates the list of solutions of such an optimisation on fine sizing, where only few (17 Nos.) best suitable solutions remain. All suitable solutions are the result of the optimisation, where minor variation in centre distance and same face width is maintained. Further the centre distance, tip and root diameters are modified to achieve the required safety factor with the minimum wall thickness requirements in an available envelope. Selecting a suitable one solution and modifying the macro geometry along with the tooth proportion can yield a satisfactory solution for our application.

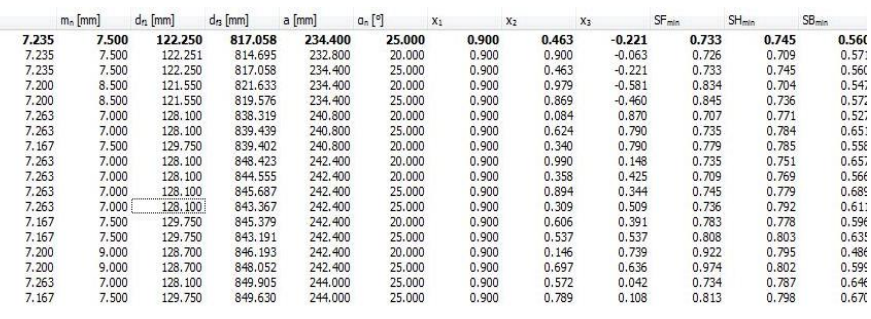

Figure 8. List of suitable solutions found after constraining the deep modification coefficient.

For low-speed high torque heavy engineering application deep addendum rack profile D (1.4 times of Module addendum \& 1times of Module dedendum) of ISO: 53 is preferred over standard tooth depth of 2.25 times of module $(1.25 \mathrm{~m}$ addendum \& $1 \mathrm{~m}$ dedendum), As it's a beneficial consequence on lever arm and tooth thickness at bottom of tooth which results in higher bending safety of the gear pair, especially for final drive application. In general, internal gears are made using a shaping process and external gears are made out of hobbing. For conventional shaping/pinion type or hobbing cutting, 
the selection of normal module, pressure angle and gear PCD is proportional to the geometry of the cutting tool. Therefore, manufacturing constraints may restrict the count of feasible solutions as the optimisation is unique for off-highway application in the manner of tooth proportion and shift coefficient for sun and planet gear. The cutter geometry is resulted from the calculation and new optimisation potential is open for sun and planet gear. But in cases of ring gear standard ISO:53 reference profile D cutter is used. Therefore, substantially faster prototype procurement and reduce the cost of developing than the special type of shaping cutter. All the cutters can be standardised in some applications where available space is high in proportion to required gear ratios.

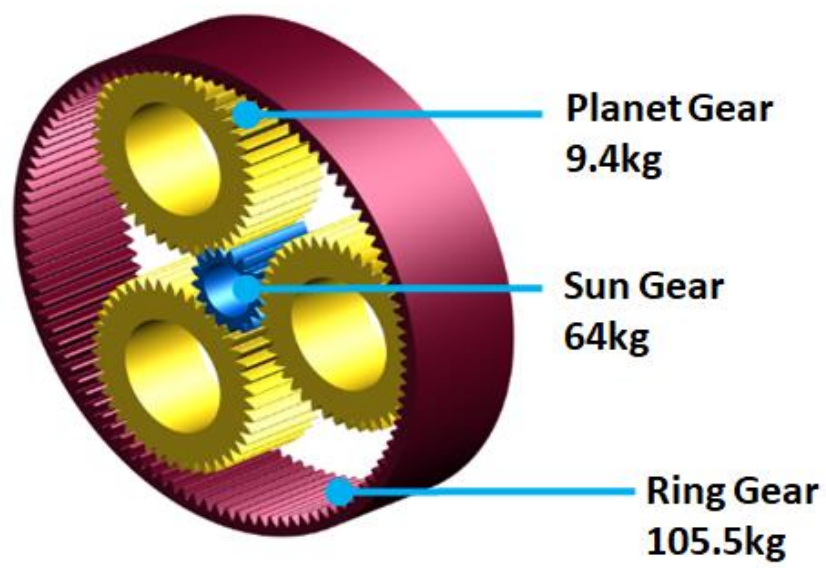

Figure 9. Pictograph of planetary gear set with optimal geometric selected solution with individual weight sun, planet and the ring gear.

Micro-geometry optimisation is the last stage of PGT modification therefore, it is mandatory to mind that bad choice of macro-geometry such as normal module, profile shift, pressure angle, etc. can never be rectified with a nice micro-geometry [11]. Selection of proper macro-geometry is prerequisite before starting the PGT layout modification [12].

\section{B. MICRO-GEOMETRY OPTIMISATION}

Micro-geometry optimisation is the final phase of optimisation where lead and profile modifications are done. To do so, it's essential for a designer to identify the primary objective function of optimisation has to be achieved, such as contact ratio, bending factor, contact factor NVH, micro-pitting, scuffing, or efficiency. Lot studies show that higher risk of micropitting is heavily influenced by lead and profile modifications [13]. Even though lead and profile modification is not new to the gear manufacturers and used for a few decades, nevertheless it is not easy to design the modification [7]. The major reason for the difficulty is that the effect of micro-geometry can be validated only with the help of loaded tooth contact analysis (LTCA) [14]. If the optimisation is done by considering individual gear pairs for designing micro-geometry, may leads to inappropriate values, for an instance a study carried out by Neil McNab, Greg Mitchum, and Erik Ostergaard on 45T baseline gear train leads to three times lesser misalignment on individual gear pair over than system level analysis [15]. System level analysis of gear pairs helps to predict actual deflections and emphasis on improved micro- geometry with minimized transmission error without increasing intensities of load on the gear pair. Performing LTCA using FEM is a complex calculation procedure and consumes ample time with a greater level of difficulty persisting for gearbox designers because several steps of calculation to be performed by the software from start of contact to end of the contact over the meshing cycle of the gear pair. Many specialised loaded tooth contact analysis software can do the task in a shorter time but evaluating multiple modifications at the same time consumes ample time [16]. To overcome the above difficulties, we used KISSsoft which is a blend of FEM based approaches in the form of complex spring models/volume models and conventional analytical approach which is on the basis of stiffness formulas, thus minimising the computing time extensively [13]. KISSsoft is used for industrial applications and can cater to higher levels of accuracy in the aspect of loaded tooth contact analysis [11\&15]. Based on benchmarked micro- 
geometry modification data such as linear tip relief and lead crowning is added to perform LTCA to identify the transmission error, efficiency and power losses of the PGT.

Figure; 10 illustrates the process flow of tooth contact analysis carried out in KISSsoft. Incorporated micro geometry values of benchmarked data are illustrated in Figure; 11.

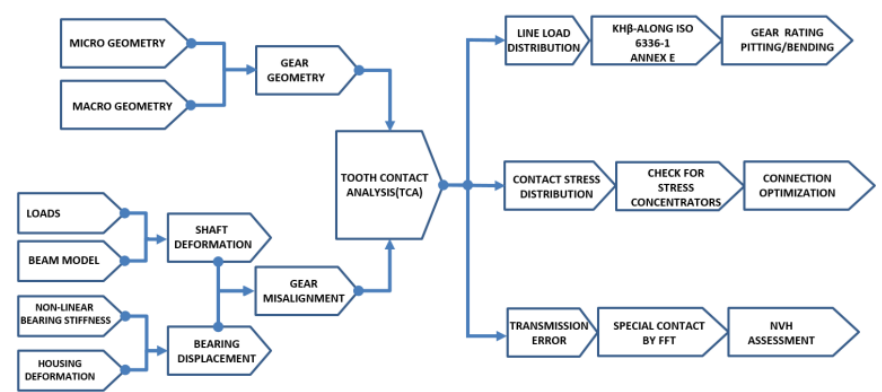

Figure 10. Design input and output of tooth contact analysis [17]

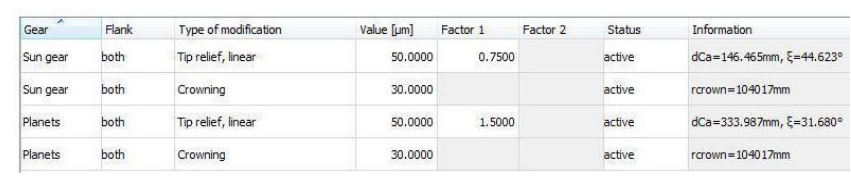

Figure 11. Micro-geometry parameters along with values and factors

There are several types of profile corrections: long or short linear corrections, long or short corrections in arc form, lead crowning, profile crowning (barreling) and others [16]. Selecting the values based on the benchmarking or adopting trial and error methods with the experience may not give fruitful results, because each individual modification and combined modification effect gives different results in terms of transmission error in system level. Automated options available in KISSsoft will perform various iterations for different modification values with respect to given range of input values along with different combinations of modification and results will be produced therefore that designers will have various options to trade-off with respect to the main requirement. Several literatures prove that the importance of profile corrections is very much more important for spur gears than that of helical gears [16] List of optimal solutions (65 solutions) are listed as the result of modification sizing. Out of 65 solutions, solution No. 10 is selected as the result of reduced transmission error of planet stage and improved efficiency under loaded condition over the benchmarked solution No.0.

Figure; 12 consists of a list of optimised microgeometry parameters and values of profile and lead crowning which is well suitable to overcome manufacturing deviation and deflection on system analysis.

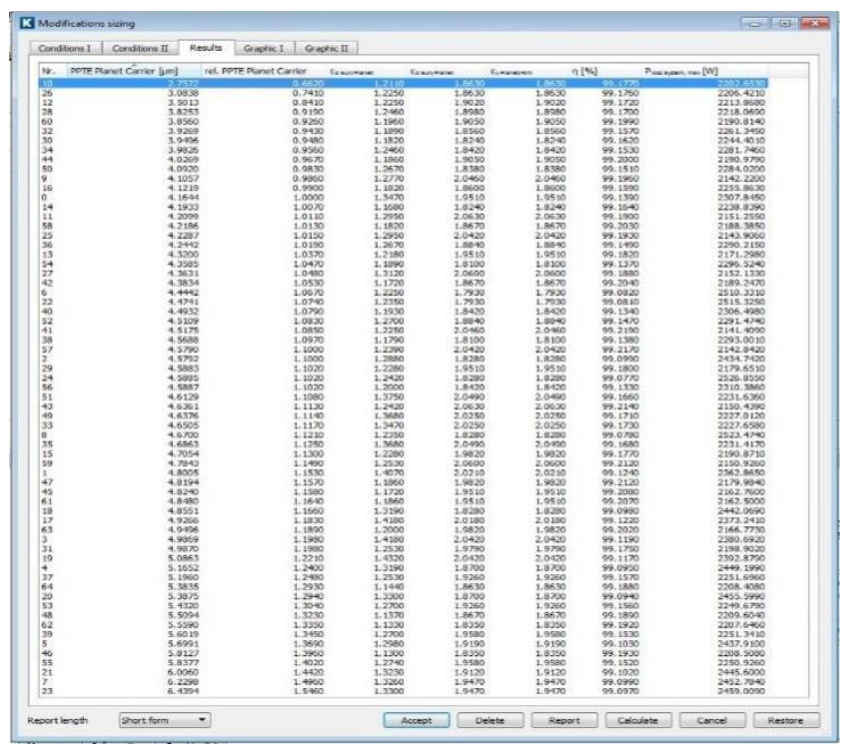

Figure 12. List of solutions as the result of modification sizing.

Radar chart on the figure; 13 and 14 gives a clear picture that solution 10 will be good-trade off of improved efficiency and transmission error over the benchmarked solution 0 . Similarly, power losses, contact ratio and maximum Hertzian pressure plotted charts can be extracted to understand the effect of different modifications in the given application. 


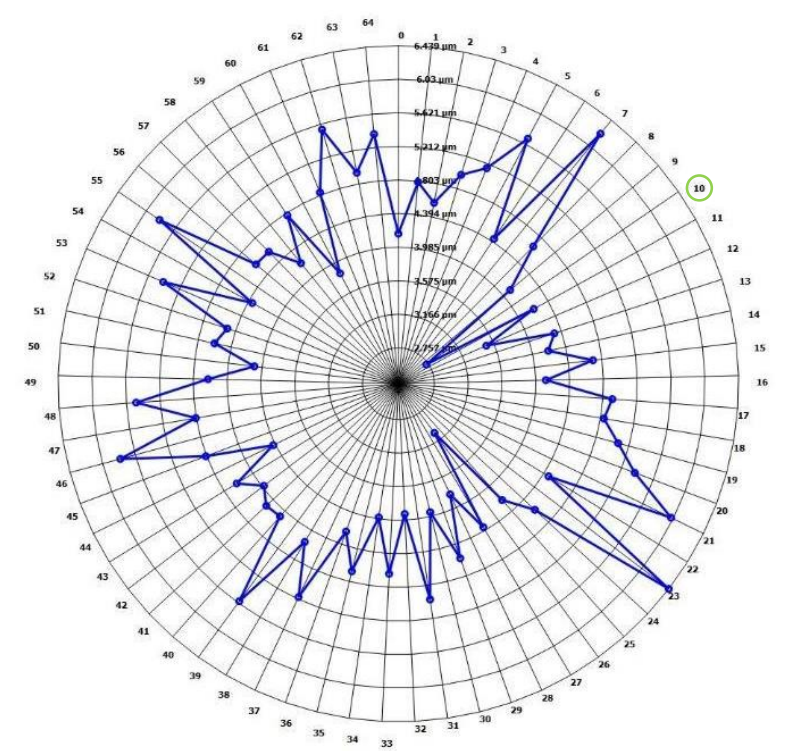

Figure 13. Comparative radar chart of PPTE for 65

solutions as the result of modification sizing

Optimised micro geometry values after the modification sizing is illustrated in Figure; 15.

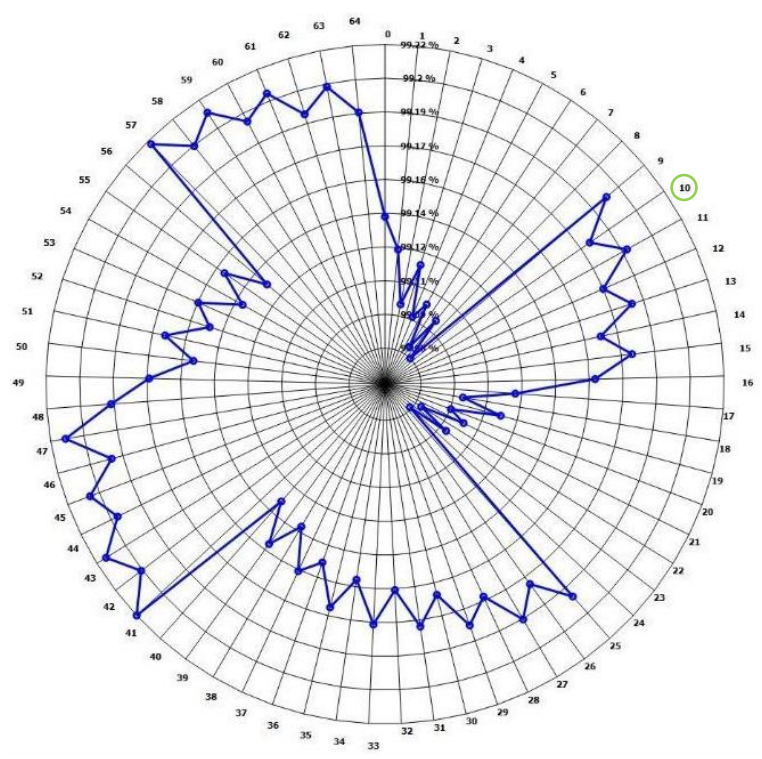

Figure 14. Comparative radar chart of efficiency for 65 solutions as the result of modification sizing

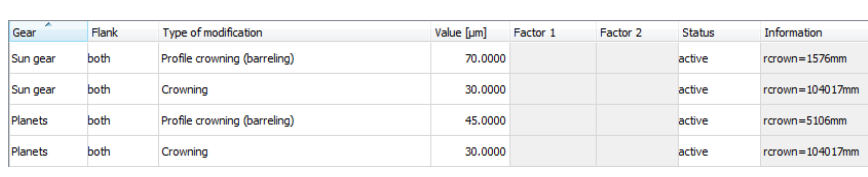

Figure 15. Optimised micro-geometry parameters along with values and factors selected after modification sizing

A mean life of the PGTs is determined from the mean lives of the critical machine elements used under dynamic loaded conditions. The existing machine elements such as bearings and shafts are used and system level evaluation carried out in the KISSsys module and results found to be satisfactory for the present study.

\section{RESULT AND DISCUSSION}

One of the prime criteria in optimisation of PGT in reduced volume is weight reduction on one hand and reduction of transmission error on the other hand. After fine sizing, predefined micro geometry values are adopted as per some gear standards information sheet on solution No.0 and further optimisation on micro geometry was carried out in an automated process called modification sizing along with loaded tooth contact analysis. After modification sizing, better micro geometry values obtained in solution No.10 over solution No.0 in the aspect of peak-topeak transmission error, efficiency and power losses. Table; 2 shows comparative list of gear geometry values, safety factors and micro geometry values of existing design Vs Solution No.0 and Solution No.10.The result of optimised solution found on solution No.10 is very well accordance for the new design in terms of root \& flank safety with improved efficiency and power losses for optimised design. Figure. 16 illustrate the compactness of optimised design over existing design. 


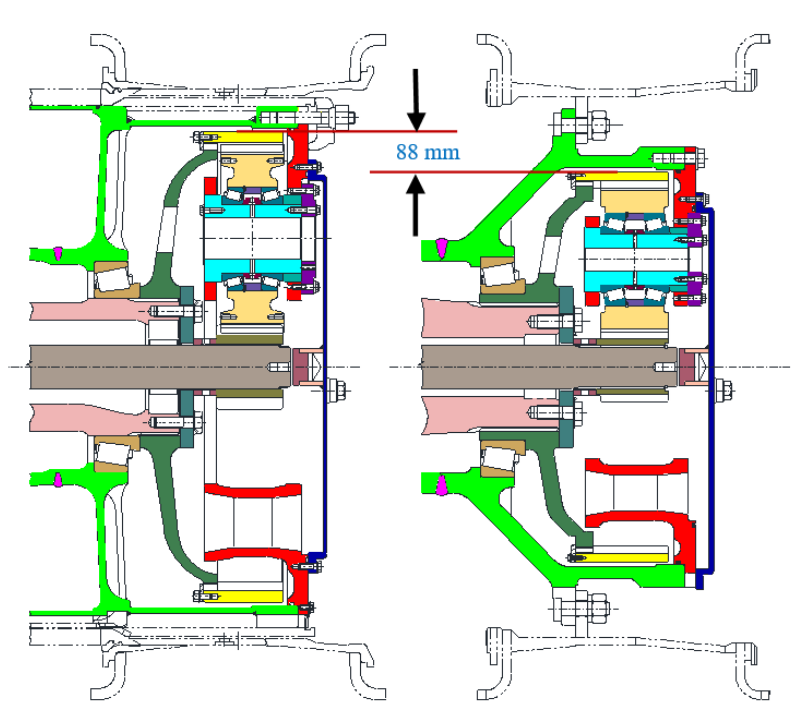

Figure 16. Existing (Left) Vs Optimised design (Right)

\begin{tabular}{|c|c|c|c|}
\hline $\begin{array}{c}\text { Parameter } \\
\text { s }\end{array}$ & $\begin{array}{l}\text { Existing } \\
\text { Design }\end{array}$ & $\begin{array}{l}\text { Solution } \\
\text { No.'0' }\end{array}$ & $\begin{array}{c}\text { Optimised } \\
\text { Solution No. } \\
\text { '10' }\end{array}$ \\
\hline \multicolumn{4}{|c|}{ Design Inputs } \\
\hline $\begin{array}{l}\text { Axle } \\
\text { Input } \\
\text { Torque }\end{array}$ & & \multicolumn{2}{|c|}{24673 N-m } \\
\hline $\begin{array}{l}\text { Axle } \\
\text { Input } \\
\text { Speed }\end{array}$ & & \multicolumn{2}{|l|}{$100 \mathrm{rpm}$} \\
\hline \multicolumn{4}{|c|}{ Packaging Aspects } \\
\hline Weight & $194 \mathrm{Kg}$ & \multicolumn{2}{|c|}{$179 \mathrm{Kg}$} \\
\hline $\begin{array}{c}\text { Centre } \\
\text { Distance }\end{array}$ & $\begin{array}{c}279.237 \\
\mathrm{~mm}\end{array}$ & \multicolumn{2}{|c|}{$233.75 \mathrm{~mm}$} \\
\hline $\begin{array}{l}\text { Ring Gear } \\
\text { O.D }\end{array}$ & $1026 \mathrm{~mm}$ & \multicolumn{2}{|c|}{$850 \mathrm{~mm}$} \\
\hline \multicolumn{4}{|c|}{ Gear Geometry } \\
\hline $\begin{array}{l}\text { Gear } \\
\text { Ratio }\end{array}$ & \multicolumn{3}{|c|}{7.235} \\
\hline $\begin{array}{l}\text { No of } \\
\text { Teeth }\end{array}$ & \multicolumn{3}{|c|}{$17 / 43 / 106$} \\
\hline Module & 9 & & 7.5 \\
\hline $\begin{array}{c}\text { Face } \\
\text { width }\end{array}$ & $\begin{array}{c}146 / 140 \\
/ 176\end{array}$ & \multicolumn{2}{|c|}{$160 / 160 / 206$} \\
\hline $\begin{array}{c}\text { Contact } \\
\text { Ratio }\end{array}$ & $\begin{array}{c}1.401 / \\
1.697\end{array}$ & \multicolumn{2}{|c|}{$1.321 / 1.707$} \\
\hline
\end{tabular}

\begin{tabular}{|c|c|c|c|}
\hline \multicolumn{4}{|c|}{ Safety Factors } \\
\hline $\begin{array}{l}\text { Root } \\
\text { Safety }\end{array}$ & $\begin{array}{c}1.86 / 1.44 / \\
1.73\end{array}$ & \multicolumn{2}{|c|}{${ }^{*} 1.61 / 1.56 / 1.61$} \\
\hline $\begin{array}{l}\text { Flank } \\
\text { Safety }\end{array}$ & $\begin{array}{c}1.04 / 1.24 \\
/ 1.74\end{array}$ & \multicolumn{2}{|c|}{${ }^{*} 1.01 / 1.19$ / 1.69} \\
\hline $\begin{array}{l}\text { Safety } \\
\text { against } \\
\text { Scuffing }\end{array}$ & $3.21 / 4.03$ & $3.22 / 4.79$ & $3.49 / 4.79$ \\
\hline Efficiency & $98.4 \%$ & $99.08 \%$ & $99.17 \%$ \\
\hline $\begin{array}{c}\text { System } \\
\text { Power } \\
\text { losses }\end{array}$ & $4.141 \mathrm{KW}$ & $2.368 \mathrm{KW}$ & $2.202 \mathrm{KW}$ \\
\hline PPTE $\Delta$ & $5.646 \mu \mathrm{m}$ & $3.008 \mu \mathrm{m}$ & $2.828 \mu \mathrm{m}$ \\
\hline \multicolumn{4}{|c|}{ Micro Geometry modification } \\
\hline $\begin{array}{l}\text { Linear Tip } \\
\text { relief }\end{array}$ & $\begin{array}{c}64 \mu \mathrm{m} / \\
1.16 \\
\text { (factor)- } \\
\text { Sun Gear } \\
\\
64 \mu \mathrm{m} / \\
1.16 \\
\text { (factor)- } \\
\text { Planet Gear }\end{array}$ & $\begin{array}{c}50 \mu \mathrm{m} / \\
0.75 \\
\text { (factor)- } \\
\text { Sun Gear } \\
50 \mu \mathrm{m} / \\
1.5 \\
\text { (factor)- } \\
\text { Planet } \\
\text { Gear }\end{array}$ & - \\
\hline $\begin{array}{c}\text { Profile } \\
\text { Crowning }\end{array}$ & - & - & $\begin{array}{c}70 \mu \mathrm{m} / 45 \\
\mu \mathrm{m}\end{array}$ \\
\hline $\begin{array}{c}\text { Lead } \\
\text { Crowning }\end{array}$ & $35 \mu \mathrm{m}$ & $30 \mu \mathrm{m}$ & $30 \mu \mathrm{m}$ \\
\hline
\end{tabular}

Table 2. Design input, gear geometry, safety factor and micro geometry values for existing design Vs solution no.0 (Before micro geometry optimisation) Vs optimised solution no.10

${ }^{*}$ Required safety factors for the new design is well above the global standard recommendations [18].

\section{CONCLUSION}

Optimising planetary gear trains is complex and it requires discrete design variables to find optimum solutions in a short duration. It is a well-known 
phenomenon that designing PGT is an iterative process that is elegant to arrive at the best suitable solution. In the present study, PGT was optimised by using KISSsoft with the objective of achieving the same reduction ratio in reduced volume. The optimised design parameters of planetary gear trains for desired output torque and speeds were disclosed in the results. Optimised new design is accommodated in a diminished outer diametrical constraint of $17 \%$ with $8 \%$ of reduction in weight with adequate root $\&$ flank safety for present application. Therefore, this methodology can be useful for designers to design from scratch as well as for optimising existing design and adopting present approach while designing PGT is rapid and flexible to make various complex changes on-the-fly.

\section{ACKNOWLEDGEMENT}

We sincerely acknowledge, S Jeyakumar,M Sasikumar, and B.H Madhusudhan, BEML, R\&D-KGF for aiding in due course of work.

\section{REFERENCES}

[1]. Takashi Osaka and Masayuki Sato, "Development of Automatic Transmission for 120Ton and 160 Ton Dump Truck," Earthmoving Industry Conference Peoria, Illinois April 9-11, 1984.

[2]. Harald Naunheimer, Bernd,Bertsche, Joachim Ryborz, Wolfgang Novak, “Automotive Transmissions: Fundamentals, Selection, Design and Application."

[3]. Richard L. Williams, Metal Products Div., Goodyear Tire \& Rubber Co. "Earthmover Rim and Wheel Development," National Combined Farm, Construction \& Industrial Machinery and Fuels and Lubricants Meetings Milwaukee, Wis. September 10-13, 1973.
[4]. KirilArnaudov and

DimitarPetkovKaraivanov,"Planetary Gear Trains."

[5]. ISO 6336-1:2006, "Basic principles, introduction and general influence factors."

[6]. DIN 3990-1:1987, "Calculation of Load capacity of Cylindrical Gears; Introduction and general influence factor."

[7]. MSc ETH I.Tsikur,KISSsoftAG,Lyon "Efficient Layout Process of Cylindrical Gears with Manufacturing Constraints." International Gear Conference. Switzerland: 2018.

[8]. Dr.Inho Bae and Dr. Ulrich Kissling, KISSsoft AG, Hombrechtikon, Switzerland, "An Advanced Design Concept of Incorporating Transmission Error Calculation into a Gear Pair Optimization Procedure." International Conference on Gears: 2010

[9]. ISO 21771:2007, "Cylindrical Involute Gear and Gear Pairs-Concepts and Geometry."

[10]. Akinci, Yilmaz, \&Canakci, "Failure of a Rotary Tiller Spur Gear.” Engineering Failure Analysis: 2005.

[11]. Ulrich Kissling, "Layout of the Gear Micro Geometry." Gear Technology, September : 2015.

[12]. Dr.Inho Bae and Dr. Ulrich Kissling, KISSsoft AG, Hombrechtikon, Switzerland, "An Advanced Design Concept of Incorporating Transmission Error Calculation into a Gear Pair Optimisation Procedure," International VDI conference. International Conference on Gears: 2010.

[13]. Dr.Ing. Ulrich Kissling, "International Calculation Method for Micropitting." Gear Technology, June: 2012.

[14]. Dr.Inho Bae and Dr. Ulrich Kissling."An advanced design concept of incorporating transmission error calculation into gear pair optimization procedure." , International Conference on Gears: 2010. 
[15]. Neil McNab, Greg Mitchum, and Erik Ostergaard, "Optimizing Gear Macro and Micro geometry To Minimize Whine and Maximize robustness for a Diesel Engine Application." Gear Technology, January: 2017.

[16]. Dr.Ing. Ulrich Kissling, "Effects of Profile Corrections on Peak-to-Peak Transmission Error" Gear Technology, July: 2010.

[17]. Dipl. Ing. ETH Hanspeter Dinner and Dr.Ing. ETH Ulrich Kissling, "An Algorithm for Robust Gear Modifications Design.” Gear Technology, July: 2012.

[18]. ISO 6336-3: 2006, "Calculation of load capacity of spur and helical gears."

[19]. Brian Dengel, "Under Pressure understand the choice of pressure angle in the design of spur or helical gearing." Gear Technology, September: 2013.

[20]. Rick Miller, "Designing very strong gear teeth by means of high pressure angles." Gear Technology, June : 2017

\section{Cite this article as :}

Suresh P R, Raghu Vamsi Patnala, "Parametric Design Optimisation of Planetary Hub Reduction Equipped in Rigid Frame Dump Truck", International Journal of Scientific Research in Science, Engineering and Technology (IJSRSET), Online ISSN : 2394-4099, Print ISSN : 2395-1990, Volume 8 Issue 2, pp. 69-80, March-April 2021. Available at doi : https://doi.org/10.32628/IJSRSET218223

Journal URL : https://ijsrset.com/IJSRSET218223 